\title{
Occlusion of Fontan fenestrations using the Amplatzer septal occluder
}

\author{
M Tofeig, K P Walsh, C Chan, E Ladusans, G Gladman, R Arnold
}

\begin{abstract}
Objective-To evaluate the efficacy and safety of the Amplatzer septal occluder device for occlusion of Fontan fenestrations.

Subjects-Five children aged 5-10 years who had undergone a fenestrated Fontan operation.

Setting-Tertiary paediatric cardiology centre.

Methods-Each patient had right and left heart catheterisation to assess haemodynamic suitability for fenestration closure. Sizing of the defect was achieved with a balloon wedge catheter and transoesphageal echocardiography. Transcatheter occlusion of the fenestration was accomplished using a $4 \mathrm{~mm}$ device in three patients, and $5 \mathrm{~mm}$ or $9 \mathrm{~mm}$ devices in the other two patients. Residual shunting following occlusion was assessed using angiography and echocardiography.

Results-100\% occlusion rate of the fenestration was achieved in all patients. No complications or device failures were seen during the three month follow up period. Conclusion-The Amplatzer septal occluder device is safe, and effectively occludes the Fontan fenestration.

(Heart 1998;79:368-370)
\end{abstract}

Keywords: Fontan circulation; fenestration occlusion; Amplatzer septal occluder device; congenital heart disease

Heart Clinic, Royal Liverpool Children's Hospital, Eaton Road, Liverpool L12 2AP, UK $M$ Tofeig

K P Walsh

C Chan

E Ladusans

G Gladman

R Arnold

Correspondence to: Dr Walsh.

Accepted for publication 23 December 1997
A residual communication or fenestration between systemic and pulmonary venous returns is often created during surgical construction of the Fontan circulation. This fenestration may prevent excessive increases in venous pressure in the early postoperative phase, especially in high risk patients. ${ }^{12}$ Many of these fenestrations close spontaneously, ${ }^{3}$ arterial desaturation and are a potential cause of paradoxical embolism. ${ }^{4}$ Subsequent closure of the fenestration using different transcatheter devices, such as double umbrellas, ${ }^{5-7}$ and coils, ${ }^{8}$ has been described. We describe our however some remain open causing persistent experience with occlusion of fenestrations using the Amplatzer septal occluder device.

\section{Patients and methods}

From February 1997, five children with Fontan circulation (table 1) underwent transcatheter occlusion of an interatrial fenestration with the Amplatzer septal occluder device (AGA Medical Corp, Golden Valley, Minnesota, USA).

OCCLUSION TECHNIQUE

All procedures were performed under general anaesthesia from the right femoral vein using a $7 \mathrm{~F}$ sheath. Arterial pressure was monitored through a small cannula inserted into the left femoral artery. Heparin was given at a dose of $100 \mathrm{IU} / \mathrm{kg}$. Mean right atrial pressure, systemic arterial pressure, and arterial and mixed venous saturations in the Fontan and left sided circulation were measured at baseline, during test occlusion, and after device placement.

A $5 \mathrm{~F}$ multipurpose catheter was used to cross the fenestration, and a $7 \mathrm{~F}$ balloon wedge catheter, passed over an exchange wire, was used to size the fenestration and to assess the effect of occlusion. Transoesophageal echocardiography was used to obtain further measurement of the fenestration, confirm complete balloon occlusion, and monitor deployment of the device. Biplane right atrial angiography was performed before and after deployment of the device.

\section{THE DEVICE}

The Amplatzer septal occluder is a self expanding, double saucer shaped device, with a central stent-like connecting cylinder. ${ }^{9} 10$ The device is formed from 720.004 " Nitinol wires braided into a cylindrical mesh. Platinum marker bands are applied to the wire ends and

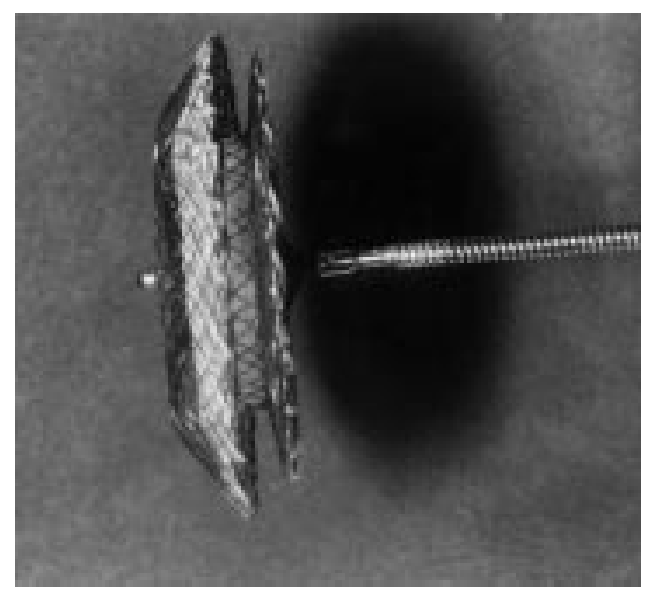

Figure 1 The Amplatzer septal occluder device.

\begin{tabular}{|c|c|c|c|c|}
\hline Case & $\begin{array}{l}\text { Sex/age } \\
\text { (years) }\end{array}$ & $\begin{array}{l}\text { Weight } \\
(\mathrm{kg})\end{array}$ & Diagnosis & Type of Fontan \\
\hline 1 & $M / 5$ & 15.1 & Double inlet left ventricle & Lateral tunnel \\
\hline 2 & $\mathrm{~F} / 5.5$ & 15.7 & Tricuspid atresia & Lateral tunnel \\
\hline 3 & $\mathrm{~F} / 6$ & 19.1 & Double inlet left ventricle & Lateral tunnel \\
\hline 4 & M/6.5 & 19.1 & $\begin{array}{l}\text { Congenitally corrected transposition; } \\
\text { pulmonary atresia }\end{array}$ & Lateral tunnel \\
\hline 5 & $\mathrm{~F} / 10$ & 22.5 & Tricuspid atresia & Lateral tunnel \\
\hline
\end{tabular}



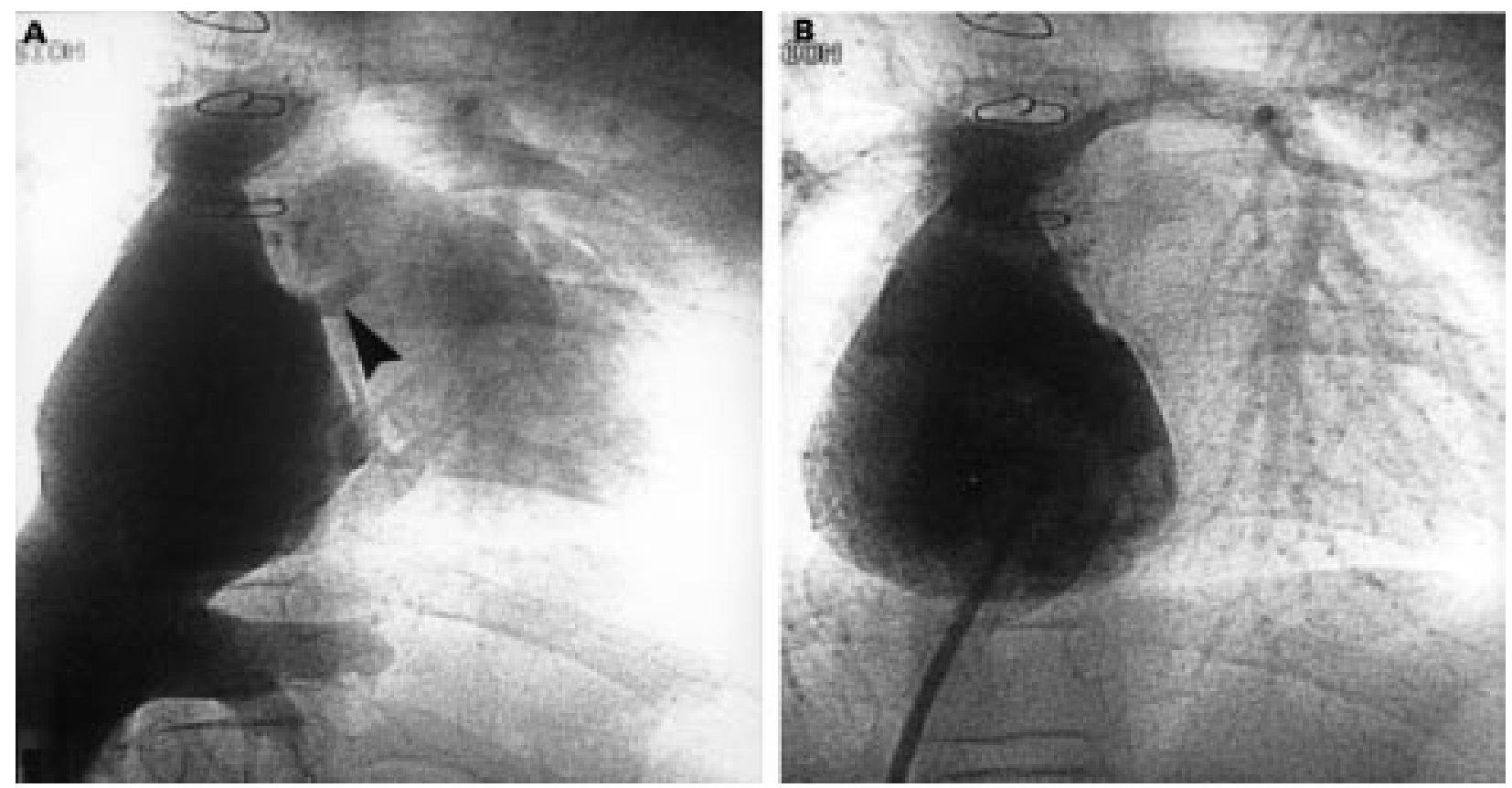

Figure 2 (A) Angiogram in the right atrium showing the fenestration before closure (arrow). (B) Angiogram in the right atrium showing the device completely occluding the fenestration.

laser welded. The shape is then formed by heat treatment. After cooling, a stainless steel sleeve with a female thread is laser welded to one of the marker bands. The defect is closed by the induction of thrombosis, which is accomplished by three polyester patches sewn into the three sections of device. Figure 1 shows the device currently under clinical evaluation with the delivery cable.

Device selection was based on the stretched diameter or known punch diameter used to create the defect. A $6 \mathrm{~F}$ or $7 \mathrm{~F}$ long sheath and dilator were passed across the defect over the exchange guidewire used for balloon sizing. The dilator and wire were removed and the sheath carefully aspirated. The delivery cable was passed through the loader and the appropriately sized occlusion device was screwed clockwise onto the tip of the delivery cable. The device and the loader were immersed in saline solution and the device was compressed by pulling it into the loader. The loader was introduced into the delivery sheath, and without rotation the device was advanced into the pulmonary venous side of the circulation. The sheath was retracted until the left atrial disc was opened on the pulmonary venous side of the baffle. The sheath and delivery cable were pulled back as one unit until the left atrial disc was snug against the pulmonary venous side of the baffle. While maintaining tension on the delivery cable, the introducing sheath was withdrawn into the Fontan circulation to deploy the tubular frame of the prosthesis in the fenestration and open the right atrial disc in the systemic venous circulation. The position of the occluder was checked with transoesophageal echocardiography before release. Once proper device position was confirmed, the device was released by turning the cable anticlockwise using a pin vise. Haemody- namic measurements and angiography were repeated (fig 2).

Three patients needed $4 \mathrm{~mm}$ devices; the other two needed $5 \mathrm{~mm}$ or $9 \mathrm{~mm}$ devices. Coil embolisation of a residual antegrade pulmonary blood flow was done during the same procedure before fenestration occlusion in one patient.

All patients received $100 \mathrm{IU}$ heparin/kg during the procedure and three doses of prophylactic antibiotics. Heparin was continued overnight if the INR was < 1.8. Patients were discharged home the following day, after chest radiography, echocardiography, and saturations were recorded. These were repeated at one and three months during outpatient visits.

\section{Results}

All patients tolerated test occlusion and device occlusion of the fenestration without significant changes in arterial or venous pressures. Arterial saturations increased from mean (SD) of $91(1)$ to $97(0.2) \%$ ( $<<0.01$; paired $t$ test). The fluoroscopy time ranged between 14 and 45 minutes.

Successful implantation of the occluder device was achieved at the first attempt in all five patients.

The immediate postimplantation angiogram revealed only a small residual leak in patient 2 , and a trivial leak in the other four patients. Subsequent follow up echocardiography at one and three months showed complete occlusion in all five patients. Oxygen saturations at one and three months follow up by pulse oximetry ranged from $92-98 \%$.

The position and integrity of the device was satisfactory and there were no complications during the three month follow up period. 


\section{Discussion}

Transcatheter occlusion of the fenestration following the Fontan procedure can be done safely and effectively using the Amplatzer device. The $100 \%$ occlusion rate on follow up echocardiograms in this small group of patients is very encouraging. We experienced no embolisation or misplacement of the device.

The Amplatzer septal occluder was designed for occlusion of left to right shunting fossa ovalis defects, ${ }^{910}$ so the device consists of two saucer shaped disks with the left sided disc overlapping the right sided disc. This design appears quite suitable for fenestration closure as the fenestrations are punched in a semicircular shaped Gore-tex patch. The saucer shaped right sided occlusion disc aligns well with the Gore-tex patch, minimising the amount of protrusion into the stagnant Fontan circulation.

Another advantage of this system is that the attachment mechanism consists of a simple screw design, and the device is easily delivered and retrieved through a $6 \mathrm{~F}$ or $7 \mathrm{~F}$ sheath. The Rashkind double umbrella has also been used to close fenestrations successfully; however, a larger delivery sheath is required or the device can be front-loaded by stripping the delivery catheter off the loading wire.

The use of transoesophageal echocardiography was helpful, although not essential, for ensuring that both discs are correctly placed before release.

In our hospital we do not routinely undertake fenestration closure in the early postoperative phase, but rather reserve it for patients with persistent desaturation from right to left shunting through the fenestration for more than one to two years after the Fontan operation. In these five patients transcatheter occlusion of Fontan fenestrations was performed because of persistent desaturation for more than one year after the surgical construction of the circulation. In one patient there had also been an episode of cerebral thromboembolism, which we ascribed to thrombus passage through the fenestration. Occlusion of the fenestrations appeared to cause no adverse haemodynamic effects; the central venous pressure was not significantly increased and there was no undue systemic venous desaturation. However, all these measurements were taken under general anaesthesia and do not necessarily reflect the capacity to increase cardiac output during exercise. So far all patients and/or parents report symptomatic improvement, although this may be related to the parents' perceptions of lack of visible cyanosis.

1 Kopf GS, Kleinman CS, Hijazi ZM, et al. Fenestrated Fon$\tan$ operation with delayed transcatheter closure of atrial septal defect. Improved results in high-risk patients. $\mathcal{F}$ Thorac Cardiovasc Surg 1992;103:1039-47.

2 Bridges ND, Mayer JE Jr, Lock JE, et al. Effect of baffle fenestration on outcome of the modified Fontan operation. Circulation 1992;86:1762-9.

3 Pearl JM, Laks H, Barthell S, et al. Spontaneous closure of enestrations in an interatrial Gore-tex patch: application to the Fontan procedure. Ann Thorac Surg 1994;57:611-14.

4 Wilson DG, Wisheart JD, Stuart AG. Systemic thromboembolism leading to myocardial infarction and stroke after fenestrated total cavopulmonary connection. Br Heart $\mathcal{F}$ 1995;73:483-5.

5 Bridges ND, Lock JE, Castaneda AR. Baffle fenestration with subsequent transcatheter closure. Modification of the Fontan operation for patients at increased risk. Circulation 1990;82:1681-9.

6 Bridges ND, Lock JE, Mayer JE Jr, et al. Cardiac catheterization and test occlusion of the interatrial communication after the fenestrated Fontan operation. $f \mathrm{Am}$ Coll Cardiol 1995;25:1712-17.

7 Redington AN, Rigby ML. Novel uses of the Rashkind ductal umbrella in adults and children with congenital heart disease. Br Heart $\mathcal{F}$ 1993;69:47-51.

8 Sommer RJ, Recto M, Golinko RJ, et al. Transcatheter coil occlusion of surgical fenestration after Fontan operation. Circulation 1996;94:249-52.

9 Melhem JA, Sharafuddin MD, Xiaoping gu MD, et al. Transvenous closure of secundum atrial septal defects: preliminary results with a new self-expanding Nitinol prosthesis in a swine model. Circulation 1997;95:2162-7.

10 Per G, Bjornstad JM, Erikk T, et al. Interventional closure of atrial septal defects with the Amplatzer device: first clinical experience. Cardiology in the Young 1997;7:277-83. 